\title{
BIOLOGICAL STUDIES OF THE PEACH FRUIT FLY, BACTROCERA ZONATA (SAUNDERS) (TEPHRITIDAE : DIPTERA) ON THREE ARTIFICIAL DIETS AT THREE CONSTANT TEMPERATURES
}

\author{
SEHAM M. EL-MAHDY ${ }^{1}$, A. H. AMIN ${ }^{2}$, AZZA K. EMAM ${ }^{2}$ \\ AND A. G. HASHEM ${ }^{1}$ \\ 1- Plant Protection Research Institute, ARC, Dokki, Giza \\ 2- Faculty of Agriculture, Ain-Shams University
}

(Manuscript received 26 May 2009)

\begin{abstract}
Effects of three artificial diets (bran, molasses and bagasse) at three constant temperatures $\left(20,25\right.$ and $\left.30^{\circ} \mathrm{C}\right)$ on some biological aspects of peach fruit fly, Bactrocera zonata, were studied under laboratory conditions. The shortest durations of immature stages (egg incubation, larval and pupal durations) were obtained at $30^{\circ} \mathrm{C}$ especially, on brain diet. Mean durations of the three immature stags were $1.76,5.25$ and 7.04 days, respectively. While the highest mean percentages of egg hatching, pupation and adult emergence were occurred on bran diet at $25^{\circ} \mathrm{C}$. Mean percentages of egg hatching, pupation and adult emergence were $92.6,90.49$ and 94.27 on bran diet at $25^{\circ} \mathrm{C}$.

However, the lowest female fecundity and percentages of egg fertility were obtained from larvae, which reared on bagasse diet at the three tested temperatures. The means were 174 eggs and $60.84 \%, 386$ eggs and $78.85 \%$ and 286 eggs and $66.43 \%$ at 20 , $25,30^{\circ} \mathrm{C}$, respectively. While, the highest female fecundity and percentages of eggs fertility were occurred on bran diet at 25 and $20^{\circ} \mathrm{C}$ being 683 eggs and $90.50 \%$ and 293 eggs and $75.88 \%$. On contrast, at $30^{\circ} \mathrm{C}$ fecundity was higher on molasses diet (438 eggs) than on bran diet (331 eggs), but eggs fertility was still the highest on bran diet $(87.08 \%)$.

Female longevity was prolonged at $20^{\circ} \mathrm{C}$ when their larvae were reared on the three diets the mean being 108.43, 124.57, 153.13 days at bran, molasses, bagasse diets, respectively. Also, male longevity was prolonged at $20^{\circ} \mathrm{C}$ when their larvae were reared on the three tested diets, it means being $96.97,111.43$ and 137.72 days, respectively.

From the obtained results, it can be concluded that bran diet was the most preferable diets for rearing $B$. zonata specially under $25^{\circ} \mathrm{C}$.
\end{abstract}

\section{INTRODUCTION}

Family Tephritidae is one of the most common families of Diptera. It includes more than 4,500 species, which distributed all over the world, out of them 50 species are regarded as major pest species on plant fruits. In Egypt Mediterranean fruit fly, Ceratitis capitata (Wied.) is considered as key pest on fruit tree. Recently, ElMinshawy et al. (1999) recorded Bactrocera zonata (Saunders) as a new pest on mango and peach fruits in Egypt. Afterwards this species was widely distributed in all gov- 
ernorates and attacked fruits of wide range of host plants (Duyck et al., 2004 and Afia, 2007).

Biological studies specially effects of temperature and diets on some biological aspects of $B$. zonata attracted attentions of several authors all over the world as well as in Egypt, i.e Qureshi et al. (1993), El-Minshawy et al. (1999) and Afia (2007) .

The aim of the present investigation was to study the effects of three constant temperatures and three artificial diets on some biological aspects of B. zonata under laboratory conditions in order to choose the optimum temperature suitable and cheapest diet for mass rearing.

\section{MATERIALS AND METHODS}

The peach fruit fly, Bactrocera zonata (Saunders) was reared in the laboratory of the Horticultural Insect Pests Department, Plant Protection Research Institute, Agricultural Research Center. Insects used in the present study were obtained from a permanent stock laboratory strain of fly kept at the peach fruit fly laboratory, Dokki, Giza. A stock culture of the fly was maintained by the rearing technique according Afia et al. (2004). The insect colonies were maintained on bran diet for six successive generations before experiment carried out.

Nine treatments, each contained five replicates were conducted in the laboratory to determine the incubation period of eggs, percentage of egg hatch, larval and pupal durations, percentages of pupation, emergence, fecundity, and fertility in addition to adults longevity were estimated for larvae, which reared on three artificial diets (bran, molasses and bagasse diets), under three constant temperatures $\left(20,25\right.$ or $30^{\circ} \mathrm{C}$ ). Means \pm SE were calculated for each duration. Temperature was adjusted by using incubators equipped with two fluorescent lights (20 watt). Light was set at 12L:12D cycle and the relative humidity were adjusted between $60-70 \%$.

Newly deposited eggs (100 eggs for each replicate) were placed in rows on moistened piece of black cloth over a sponge saturated with tap water in a Petri dish. Egg hatch was observed every 12 hours using a stereomicroscope. The newly hatched larvae were transferred to open plastic cups containing larval diets. The three artificial diets were prepared according to Bran diet (Afia et al., 2004), Molasses diet (Awadallah and El-Hakim, 1987) and bagasse diet (Foda et al., 1989). The cups were kept in a bigger plastic container with a layer of fine sand under the three constant temperatures. Usually, mature larvae were jumped outside the trays to pupate in sand. Pupation was daily recorded.

The newly formed pupae of each diet were separated from the sand using a sieve and the newly formed pupae was collected at the same day and counted. Each 
pupa was placed in a plastic tube $(3 \times 1 \mathrm{~cm})$ and covered with white muslin for aeration. The tubes were kept under the three tested constant temperatures. Adult emergence and percentage of emergence were recorded. When the majority of the adult had emerged and after four hours, thirty pairs of newly emerged adults (30 males and 30 females) were selected at random and kept in a small transparent plastic cage $(15 \times 15 \times 10 \mathrm{~cm})$, provided with wet cotton as a source of water and sugar, protein hydrolysate as food. After mating, females started oviposition. The laid eggs were removed daily from each replicate and kept on moistened piece of black clothes in Petri dish under the three tested constant temperature. The eggs were counted and number of hatching eggs represented the fertility was recorded. The number of the laid eggs was considered as measure of fecundity. Adult mortality in the cages also was recorded daily for determining the longevity for both sexes.

Results obtained were subjected to statistical analysis of variance by using Proc ANOVA in SAS (SAS Institute, 1998). When $\mathrm{F}$ value was significant separation between means were conducted by using LSD procedure in the same program.

\section{RESULTS AND DISCUSSION}

Results obtained for different biological aspects of Bactrocera zonata reared on three artificial diets at three constant temperatures are given in Tables (1\&3). Results of statistical analysis are given in Tables (2 \& 4).

\section{Egg stage}

The time required for egg development is represent egg incubation period. Results of statistical analysis showed significant difference between means of egg incubation at the three tested temperatures, which reared on three artificial diets. The shortest mean of incubation period was 1.76 days occurred at $30^{\circ} \mathrm{C}$ on bran diet, while the longest mean of incubation period was 5.34 days occurred at $20^{\circ} \mathrm{C}$ on bagasse diet. 
1028 BIOLOGICAL STUDIES OF THE PEACH FRUIT FLY, BACTROCERA ZONATA (SAUNDERS)

(TEPHRITIDAE : DIPTERA) ON THREE ARTIFICIAL DIETS AT THREE CONSTANT TEMPERATURES

Table (1) 
Also results indicated that at $30^{\circ} \mathrm{C}$ means of incubation periods reached their lowest means when reared on the three diets being $1.76,2.48$ and 2.97 days which reared on bran, molasses and bagasse diets, respectively . On the contrary, at $20^{\circ} \mathrm{C}$ means of incubation periods reached their maximum when reared on the three diets being $3.84,4.81$ and 5.34 days, which reared on the three tested diets, respectively.

From these results, it could be stated that incubation period was decreased gradually as temperature increased.

These results are similar to those obtained by El-Minshawy et al. (1999), Amin (2003) and El-Naggar (2004).

Regarding the percentage of egg hatchability, statistical analysis showed highly significant differences between means. The highest percentage of egg hatchability was occurred at $25^{\circ} \mathrm{C}$ for eggs on bran diet $(92.6 \%)$, while the lowest percentages was occurred at $20^{\circ} \mathrm{C}$ for eggs reared on bagasse diet (58.2\%). Also results showed that high egg hatchability \% were occurred when reared on bran diet used at the three tested constant temperatures, the means being $78.4,92.6$ and $88.6 \%$ for 20,25 and $30^{\circ} \mathrm{C}$, respectively. While the lowest percentages of hatchability were 58.2, 79.8 and $68.8 \%$ at the three temperatures when used bagasse diet, respectively. From these results, it could be stated that bran diet at $25^{\circ} \mathrm{C}$ found to be the most favorable conditions.

These results are in harmony with those obtained by Qureshi et al. (1993), Amin (2003), El-Naggar (2004) and Afia (2007). On the contrary, these results differ from those obtained by Duyck et al. (2004), who recorded 10, 54, 71, 58 and 18\% egg hatch at $15,20,25,30$ and $35^{\circ} \mathrm{C}$, respectively. 
1030 BIOLOGICAL STUDIES OF THE PEACH FRUIT FLY, BACTROCERA ZONATA (SAUNDERS)

(TEPHRITIDAE : DIPTERA) ON THREE ARTIFICIAL DIETS AT THREE CONSTANT TEMPERATURES

Table (2) 


\section{Larval stage}

Statistical analysis showed significant difference between means of larval duration, which reared on the three tested diets at the three constant temperatures. The shortest mean duration of larval stage was occurred at $30^{\circ} \mathrm{C}$ (5.25 days ) reared on bran diet, while the longest mean duration was occurred at $20^{\circ} \mathrm{C}$ (17.16 days ) reared on bagasse diet. Regarding the effects of diets on larval duration, results showed the shortest means larval duration were occurred for larvae reared on bran diet being $12.66,7.76,5.25$ days at 20,25 and $30^{\circ} \mathrm{C}$, respectively. While the longest means were occurred for larvae reared on bagasse diet being 17.16, 9.65 and 7.87 days at three tested temperatures, respectively.

From these results it could stated that both temperature and diets significantly affected the larval duration. Bran diet at $30^{\circ} \mathrm{C}$ found to be the most favorable conditions for rearing larvae

These results are closely related to those obtained by El-Minshawy et al. (1999), Amin (2003), Duyck et al. (2004) and Afia (2007) who found that the larval periods were $9.7,8.87$ and 8.47 and 5 days when larvae reared on bran diet at $25^{\circ} \mathrm{C}$. On the other hand, longer duration was reported by El-Gendy (2002) who found that the larval duration was 10.37days when reared larvae on molasses diet under laboratory conditions.

Regarding percentage of pupation, statistical analysis showed significant difference between means. The highest mean percentage of pupation was occurred for larvae reared on bran diet at $25^{\circ} \mathrm{C}(90.49 \%)$, while the shortest mean was occurred for larvae reared on bagasse diet at $20^{\circ} \mathrm{C}(39.86 \%)$. Also results showed that the three tested diets affected percentage of larval pupation at three tested temperatures. The highest mean percentages were occurred for larvae reared on bran diet being 74.74, 90.49 and $87.72 \%$ at 20,25 and $30^{\circ} \mathrm{C}$, respectively. While the lowest mean percentages were occurred for larvae reared on bagasse being 39.86, 75.44 and $56.98 \%$ at three tested temperatures, respectively.

From the above-mentioned results, it could be stated that bran diet at $25^{\circ} \mathrm{C}$ found to be the most favorable conditions for rearing larvae.

These results are similar to those obtained by El-Minshawy et al. (1999), Amin (2003) and Afia (2007).

\section{Pupal stage}

Statistical analysis showed that means of pupal duration were significantly affected by both temperature and larval diets. The shortest mean of pupal duration was occurred at $30^{\circ} \mathrm{C}$ on bran diet (7.04 days). While the longest means pupal durations was occurred at $20^{\circ} \mathrm{C}$ on bagasse diet (20.69 days) 
Regarding effects of the three tested diets on pupal mean duration, results revealed that the shortest means of pupal duration occurred for larvae reared on bran diet at the three tested temperature being $16.88,10.73$ and 7.04 days at 20,25 and $30^{\circ} \mathrm{C}$, respectively. While the longest means of pupal duration were occurred for those reared on bagasse being 20.69, 14.09 and 9.47days on the three tested temperatures, respectively.

The results similar to those obtain by Qureshi et al. (1993), El-Minshawy et al. (1999), Amin (2003), Duyck et al. (2004) and Afia (2007). While, Binay and Agarwal (2005) reported shorter pupal durations (8.4 days) on guava fruits.

Regarding effects of both temperature and diets on percentage of adult emergence, statistical analysis showed significant difference between means. The highest mean percentage occurred at $25^{\circ} \mathrm{C}$ for larvae reared on bran diet (94.27\%). While the lowest mean occurred at $20^{\circ} \mathrm{C}$ for larvae reared on bagasse diet (64.65\%). 
Table (3) 
With regards to effects of larval diets on mean percentages of adult emergence results showed that the highest mean percentages were occurred for larvae reared on bran diet at the three tested temperatures being $80.20,94.27$ and $92.36 \%$ at 20 , 25 and $30^{\circ} \mathrm{C}$, respectively. While the lowest mean percentages were occurred for larvae reared on bagasse diet at the three tested temperature being $64.65,83.72$ and $74.48 \%$ for the three tested temperature, respectively.

From the above mentioned results it could be stated that bran diet at $25^{\circ} \mathrm{C}$ seemed to be the most favorable conditions to obtained the highest percentage of adults emergence.

These results are in harmony to those obtained by Duyck et al. (2004), ElNaggar (2004) and Afia (2007) .

\section{Adult stage}

During longevity of adult female it passed through three periods, preoviposition, oviposition and post-oviposition periods.

Results of statistical analysis for these data is given in table (4). It found more convenient to discuss results for each item separately.

\section{Pre-oviposition period}

Results showed that both factors insignificantly affected pre-oviposition period. However, the shortest mean of pre-oviposition period was occurred at $30^{\circ} \mathrm{C}$ on bran diet (9.61days), While the longest period was occurred at $20^{\circ} \mathrm{C}$ on bagasse diet (27.18 days). Also, the shortest means of pre-oviposition period were occurred when larvae reared on bran diet at three tested temperature being 22.29, 13.68 and 9.61days at 20,25 and $30^{\circ} \mathrm{C}$, respectively. While the longest means of pre-oviposition period were occurred when larvae reared on bagasse being 27.18, 16.59 and 13.16 at 20,25 and $30^{\circ} \mathrm{C}$, respectively.

From these results, it could be stated that both temperature and larval diets were insignificantly affected on the pre-oviposition period of adult females.

These results closely related to those obtained by El-Gendy (2002), El-Naggar (2004), and Afia (2007).

\section{Oviposition period}

Results of statistical analysis revealed that both temperature and diets significantly affected oviposition period of adult females. The longest mean oviposition period was occurred at $20^{\circ} \mathrm{C}$ for larvae reared on bagasse (113.52 days). While, the shortest mean oviposition period was occurred at $30^{\circ} \mathrm{C}$ for larvae reared also on ba- 
gasse diet (33.20 days). However, the three tested larval diets showed miscellaneous effects on means oviposition period at the three constant temperatures.

From these results, it seemed that oviposition period of adult females mainly affected by prevailing temperature.

These results are similar to these obtained by El-Gendy (2002), El-Naggar (2004) and Afia (2007). However, Rana et al. (1992) recorded 14.8 days for this period on bran artificial diets.

\section{Post -oviposition period}

Statistical analysis showed insignificant effects of both temperature and diets on post-oviposition periods. However, the longest mean of post -oviposition period was occurred at $20^{\circ} \mathrm{C}$ for larvae reared on bagasse diet (12.43 days). While the shortest one was occurred at $30^{\circ} \mathrm{C}$ for, larvae reared on bran diet (4.76 days). Meanwhile the three tested larval diets showed miscellaneous effects on means post-oviposition period at three constant temperatures. 
1036 BIOLOGICAL STUDIES OF THE PEACH FRUIT FLY, BACTROCERA ZONATA (SAUNDERS)

(TEPHRITIDAE : DIPTERA) ON THREE ARTIFICIAL DIETS AT THREE CONSTANT TEMPERATURES

Table (4) 
From these results, it seemed that post- oviposition period of $B$. zonata females were mainly affected by prevailing temperature.

These results are in harmony with those obtained by Afia (2007) who recorded $8.35,5.84$ and 3.89 days for this period on bran diet at 20,25 and $30{ }^{\circ} \mathrm{C}$, respectively. On contrary, Rana et al. (1992) and El-Minshawy et al. (1999) recorded 28 and 12-16 days on bran and carrot diets, respectively.

\section{Longevity of adult female}

Statistical analysis showed significant effects of temperature on mean longevity of adult females. The longest mean of female longevity was 153.13 days, which occurred at $20^{\circ} \mathrm{C}$ for larvae reared on bagasse diet. While the shortest mean longevity was 52.64 days was occurred at $30^{\circ} \mathrm{C}$ also one bagasse diet. However, the three tested larval diets showed miscellaneous effects on means longevity of adult females at three constant temperatures.

From afore mentioned results it seemed that adult female longevity mainly affected by prevailing temperature.

These results are similar to those obtained by El-Minshawy et al. (1999), ElGendy (2002) and Afia (2007). On the contrary, Rana et al. (1992) and Amin (2003) recorded the longevity of female as 58.2 and 43.20 days on bran artificial diet, respectively.

\section{Fecundity and Egg fertility}

Statistical analysis showed highly significant effects of both temperature and larval diets on females fecundity as well as egg fertility. The highest mean fecundity was 683 eggs/female occurred at $25^{\circ} \mathrm{C}$ for larvae reared on bran diet. While the lowest mean fecundity was 174 eggs/female occurred at $20^{\circ} \mathrm{C}$ for larvae reared on bagasse diet. Regarding mean percentage of egg fertility results showed the highest mean percentage was $90.50 \%$ occurred at $25^{\circ} \mathrm{C}$ for larvae reared on bran diet. While the lowest mean percentage of fertility was $60.84 \%$ at $20^{\circ} \mathrm{C}$ for larvae reared on bagasse diet.

With regards to effects of the three tested diets on means fecundity of female at three constant temperatures, results showed that larvae, which reared on bran diets at $20 \& 25^{\circ} \mathrm{C}$ gave the highest means of females fecundity being 293 and 683 eggs/female, respectively. While at $30^{\circ} \mathrm{C}$ the highest mean of fecundity obtained for larvae reared on molasses diet.

Results showed that highest percentages of egg fertility were occurred for larvae reared on bran diet at the three-tested temperature. The means were $75.88,90.50$ and $87.08 \%$ at 20,25 and $30{ }^{\circ} \mathrm{C}$, respectively. While the lowest egg fertility were $60.84,78.85$ and $66.43 \%$ occurred for larvae reared on bagasse diet at 20,25 and $30^{\circ} \mathrm{C}$, respectively. 
From these results, it could be stated that bran diet at $25^{\circ} \mathrm{C}$ seemed to be the most favorable conditions for $B$. zonata.

These results similar to those obtained by El-Minshawy et al. (1999) and Afia (2007). On the contrary, Duyck et al. (2004) found percentages of egg fertility was the lowest (46, 70 and $49 \%$ at 20,25 and $30^{\circ} \mathrm{C}$ ), respectively.

\section{Longevity of adult male}

Statistical analysis showed significant effects of temperature on longevity of adult males. The longest mean of male longevity was 137.72 days, which occurred at $20^{\circ} \mathrm{C}$ for larvae reared on bagasse diet. While the shortest longevity was 52.80 days was occurred at $30^{\circ} \mathrm{C}$ also one bagasse diet. However, the three tested larval diets showed miscellaneous effects on longevity of adult males at three constant temperatures.

From these mentioned results it seemed that adult male longevity mainly affected by prevailing temperature.

These results are similar to those obtained by El-Minshawy et al. (1999) who recorded 100 days as the longevity of male flies reared on bran artificial diet.

\section{REFERENCES}

1. Afia, Y. E. 2007. Comparative studies on the biology and ecology of the two fruit flies, in Egypt Bactrocera zonata (Saunders) and Ceratitis capitata (Wiedemann). Ph.D. Thesis, Fac. Agric. Cairo. Univ. Egypt, 301 pp.

2. Afia, Y. E., M. A. El-Sheikh, A. G. Hashem and S. El-Nagar. 2004. Influence of different constant temperatures on the biological aspects of two fruit flies (Diptera : Tephritidae ) in Egypt. Egypt. J. Appl .Sci ., 20 (7) : 257-276 .

3. Amin, A. A. 2003. Studies on the peach fruit fly, Bactrocera zonata (Saund.) and its control in Fayoum Governorate. M. Sc. Thesis, Fac. Agric., Fayoum University. $143 p p$

4. Awadallah, A. M. and A. M. El-Hakim. 1987. Methods for mass production of the Mediterranean fruit fly, Ceratitis capitata (Wied). Methods for producing adults. Zagazig J. Agric. Res., No. 14 : 709-719.

5. Duyck, P. F., J. F. Sterin and S. Quilici. 2004. Survival and development of different life stages of Bactrocera zonata (Diptera: Tephritidae) reared at five constant temperatures compared to other fruit fly species. Bull. Entomol. Res., 94: 89-93.

6. El-Gendy, I. R. I. 2002. Studies on Peach fruit fly, Bactrocera zonata (Saund.) at ElBeheira Governorate. M. Sc. Thesis, Fac. Agric., Alexandria Univ., 127 pp. 
7. El-Minshawy, A. M., M. A. El-Eryan and A. I. Awad 1999. Biological and morphological studies on the guava fruit fly Bactrocera zonata (Saunders) (Diptera:Tephritidae) found recently in Egypt. 8th Nat. Conf. Pests \& Dis of Veg. \& Fruits in Ismailia, Egypt, 71-82.

8. El-Naggar, H. M. 2004. Studies on some apple insect pests. M. Sc. Thesis, Fac. Agric., Zagazig University .116 pp.

9. Foda, S. N., A. G. Hashem and M. H. Saafan. 1989. Some biological aspects of the Mediterranean fruit fly, Ceratitis capitata (Wied.) on an artificial diet. J. Agric. Res., 67 (1): 49-54.

10. Qureshi, Z. A., T. Hussain T. R. Carey and R. V. Dowell 1993. Effect of temperature on development of Bactrocera zonata (Saunders) (Diptera: Tephritidae). Pan Pacific Entomologist, 69 (1): 71-76.

11. Rana, J. S. O. M. Parkash and S. K. Verma. 1992. Biology of guava fruit fly infesting guava in Haryana and influence of temperature and relative humidity on its incidence crop. Research Hisar., 5 (3): 525-529 .

12. SAS Institute. 1998. SAS static user. SAS Institute. Cary NC. U.S.A. 


\section{دراسة بيولوجية علي ذبابة ثمار الخوخ المرياة علي ثلاث بيئات صناعية \\ لليرقات تحت ثلاث درجات حرارة ثابتة تحت الظروف المعملية}

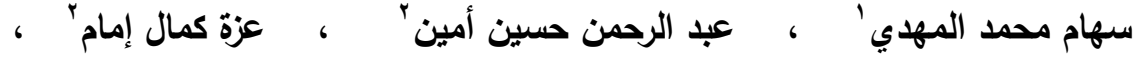
عبد الفتاح جاد هاشم'

$$
\text { r- - كلية الزراعة - جاث وقاية النباتات - مركز البحوث الزراعية - الدقي - جيزة }
$$

تم تربية البرقات علي ثلاث بيئات صناعية (الردة - المولاس - مصاصة القصب) وذلك علي

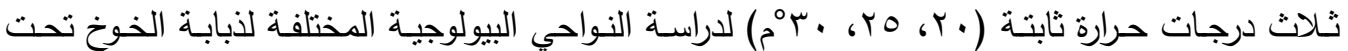

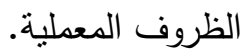

تثئير الننائج الي أن أقصر فترات للأطوار غير الكاملة (بيض - برقات - عذاري) حدثت علي

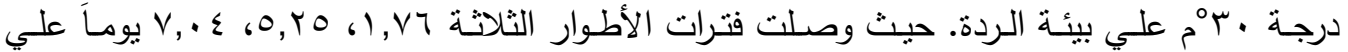

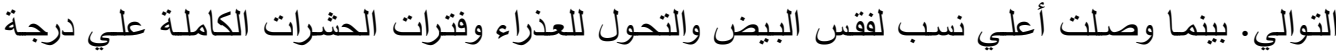

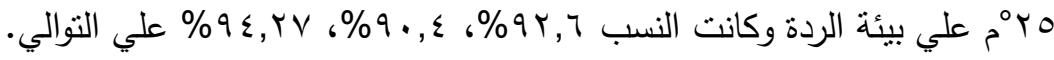
بالنسبة لمقدرة الأنثي علي وضع البيض وخصوبة البيض فقد وصلت لأدني مستوياتها لليرقات

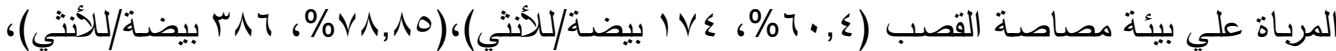

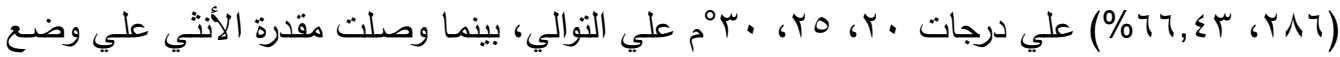

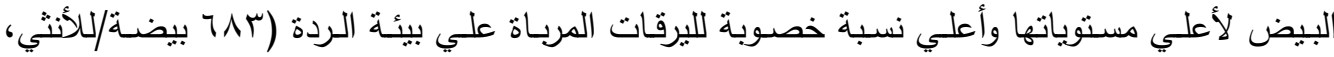

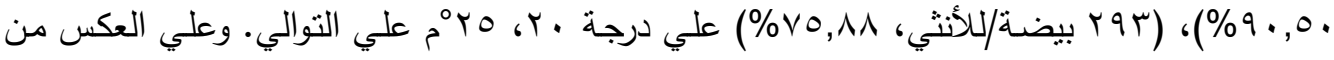

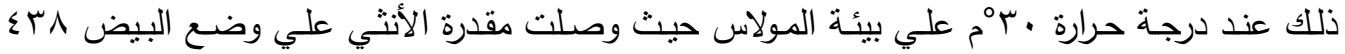

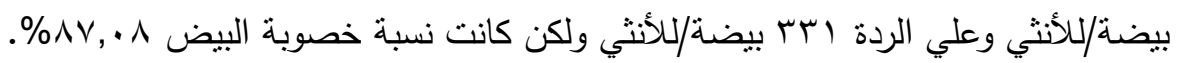

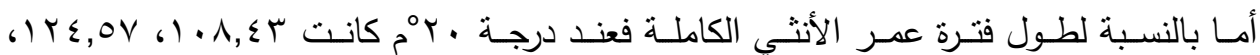

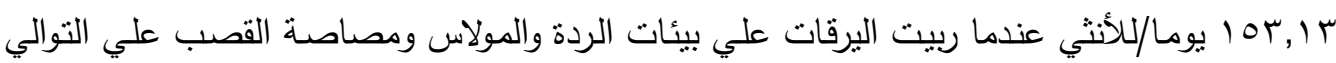

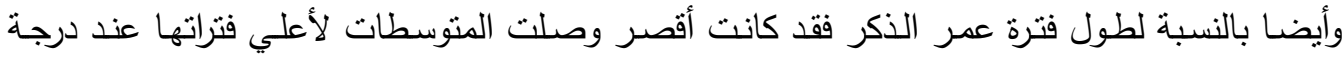

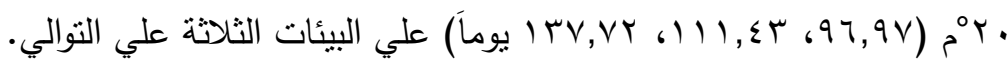

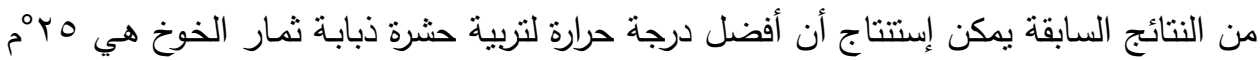

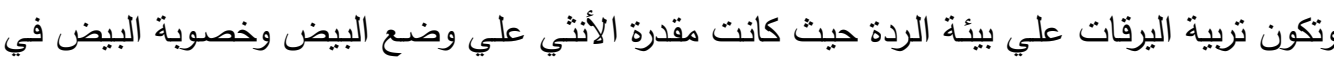
أعلي مستوياتها وأقل نسبة موت وأقصر فترات الحياة لجميع الأطوار . 